\title{
Cardiorespiratory and muscular endurance of sedentary children and adolescents with or without intellectual disability in the Democratic Republic of Congo
}

\author{
Teddy Bofosa ${ }^{1}, \oplus$ Betty Miangindula ${ }^{1}, \oplus$ Constant Nkiama $^{1}$, $\odot$ Eric Kam ${ }^{1}$, \\ - Guy Bumoko ${ }^{2}$
}

${ }^{1}$ Department of Physical Medicine and Rehabilitation, Faculty of Medicine, University Clinics of Kinshasa, Democratic Republic of Congo. ${ }^{2}$ Neuro-Psychopathological Center, Faculty of Medicine, University Clinics of Kinshasa, Democratic Republic of Congo.

\begin{abstract}
The aim of this study was to assess the level of physical fitness and sedentary children with disabilities included in Kinshasa. One hundred-thirty children were included in this study, 70 with intellectual disability (ID, age: $12.4 \pm 4$ years) and 60 without ID (age: $11.6 \pm 4$ years). Flexibility, explosive strength, grip strength, abdominal endurance and cardiorespiratory endurance tests were used. They are supplemented by the measurement of anthropometric characteristics. Measurements of muscular strength endurance, isometric force, walking distance and cardiorespiratory endurance were significantly higher in comparison with ID ( $\mathrm{p}<0.05)$. The muscular strength endurance, isometric strength walking distance and cardiorespiratory endurance of girls were significantly lower than those of the control group $(p<0.05)$. It is clear from this study that the cardiorespiratory and muscular endurance of children and adolescents with intellectual disabilities is inferior to those of children without intellectual disabilities regardless of the type of children.
\end{abstract}

Keywords. Adolescents, children, endurance, intellectual disability, sedentarity.

\section{Introduction}

Nowadays, the sedentary lifestyle is the fourth risk factor for mortality according to the World Health Organization (WHO) at the global level. It does not correspond to the absence of activity, but is defined as activities with reduced movements and which are not a source of a significant energy expenditure (because too close to the resting metabolism). In children and adolescents, regular physical activity promotes the development of a healthy musculoskeletal and cardiovascular system (Owen et al., 2014). It also allows them to learn to coordinate and control their movements and to maintain an adequate level of fitness. Moreover, regardless of the level of physical activity practiced, physical inactivity is also a risk factor in terms of health; this increases the risk of mortality by 20 to $30 \%$ (WHO, 2015). In terms of public health, it is therefore important to study the lifestyle of individuals in terms of physical activity and sedentary lifestyle. The data on physical activity and sedentary behavior of the Congolese population are focused on valid persons (WHO, 2014). No studies have been conducted to collect data on the fitness level of persons with disabilities whose statistics are poorly developed. To date, only surveys that are poorly documented and generally conducted by organizations (national 
and international) for people with disabilities in a part of the country have been used to identify people with disabilities. There are thus about $10,500,000$ disabled people in the Democratic Republic of Congo (DRC), which represents nearly $13 \%$ of the Congolese population (INS, 2010). ID is common, with approximately 1 to $2 \%$ of the global population being affected (Politte \& Dougle, 2014).

Children with intellectual disability (ID) present significant limitations of adaptive functioning, visible in various skill areas such as communication, school learning, autonomy, individual responsibility, social life, work, leisure, health, or still security (Welk et al., 2010; GonzalezAguero et al., 2010). The survival of these children in the DRC is marked by a lack of encouragement to the practice and / or information of parents or educators this promotes physiological deconditioning but also psychological and leads these children to remain more and more sedentary. Given the sedentary lifestyle of children and teenagers with ID, we were motivated to carry out this study with the aim of finding out how this sedentary lifestyle affects the physical condition of these children and compared to children without children intellectual disability.

\section{Methods}

One hundred and thirty (130) subjects were selected to participate in this study including 70 with ID (40 boys and 30 girls) and 60 without ID (30 boys and 30 girls). The inclusion criteria below are retained: to be regularly registered at the Tuendeleye health center in Lemba commune or at the Bopikiliki Kinshasa institute (Democratic Republic of Congo) during the study; have been diagnosed with a developmental disability by a doctor and a psychologist; have an intelligence quotient of less than 70 for children with ID; be between 6 and 17 years old be present for all evaluations; freely accept to participate in the study. Excluded were anyone who did not meet the inclusion criteria.

This study was conducted according to rules defined by the directives and audits of the local ethics commission. All parents of children and adolescents with or without ID have signed a consent to their children's participation.

\section{Motor Tests}

As recommended by the American College of Sport Medicine, physical fitness should be assessed by a set of measures that include at a minimum: body composition, aerobic fitness, flexibility, and strength (American College of Sports Medicine, 2014).

In our work, the physical condition was evaluated using 5 tests from the EUROFIT battery (Pace \& Bricout, 2015). The tests that have been selected are below.

\section{The flexibility test}

It is measured using the "sit-and-reach" test where the child sits on the floor with legs outstretched and should extend the arms as far as possible towards the toes. The distance $(\mathrm{cm})$ between the fingertips and the heels is measured. This measure may be negative for weak and supple subjects if the hands go beyond the toes for soft subjects.

\section{The explosive force test}

It is measured using a horizontal relaxation test, evaluated with a horizontal jump forward, feet joined and without momentum. The gap between the starting line and the mark of the heels after the jump is measured $(\mathrm{cm})$.

\section{The endurance test of muscular strength}

It is evaluated for the muscles of the trunk. It consists of performing a maximum of bending of 
the trunk in 30 seconds, in elongated starting position. The subject must reach the sitting position on the legs flexed at $90^{\circ}$ at the end of flexion of the trunk. The measurement obtained is expressed by the number of flexion made in 30 seconds.

\section{The isometric strength test}

It measures a voluntary maximum force (FMV) using a hand grip equipped with a measuring sensor (FK 500) which records the clamping force of the hand. The maximum voluntary force is evaluated for both hands (Newton). We retained the score of the best of both hands.

\section{The six-minute walk test}

The child must walk as far as possible for six minutes. Then using a specific equation (Sinivasan et al., 2014), the maximum oxygen consumption is calculated, according to the following formula: $\mathrm{VO}_{2}$ $(\mathrm{ml} / \mathrm{kg} / \mathrm{min})=49.9-1.0(\mathrm{x})$ where $\mathrm{x}$ is the distance traveled for 6 minutes.

\section{Statistical Analyzes}

Quantitative variables are presented as mean \pm standard deviation. The girls / boys comparisons with and without DI were performed by a student $t$ test in the SPSS software version 21.0. A threshold of significance at $\mathrm{p}<0.05$ was retained.

\section{Results}

The results show no significant difference in demographic characteristics between girls and boys with or without ID (Table 1).

Boys with ID showed significantly lower muscular endurance, strength and cardiorespiratory endurance than boys without ID (Table 2).

Table 1

Demographic characteristics.

\begin{tabular}{lcccc}
\hline \multirow{2}{*}{ Variables } & Girls & With ID & \multicolumn{2}{c}{ Without ID } \\
& $11.8 \pm 6$ & Boys & Girls & Boys \\
\hline Age (year) & $1.5 \pm 0.2$ & $13.1 \pm 2.6$ & $13.3 \pm 2.9$ & $12.4 \pm 4$ \\
Height $(\mathrm{m})$ & $46.3 \pm 4.6$ & $1.4 \pm 0.3$ & $1.5 \pm 0.1$ & $1.4 \pm 7.1$ \\
Weight $(\mathrm{kg})$ & $20.4 \pm 3.7$ & $45.2 \pm 6.1$ & $48 \pm 2.9$ & $46.5 \pm 5.6$ \\
BMI $\left(\mathrm{kg} / \mathrm{m}^{2}\right)$ & $77 \pm 2.2$ & $23.06 \pm 1.7$ & $21.33 \pm 6.3$ & $23.72 \pm 3.9$ \\
IQ & $80.4 \pm 0.6$ & $49.1 \pm 8.1$ & $50.7 \pm 2.7$ \\
\hline
\end{tabular}

BMI: body mass index; IQ: intellectuel quotient

Table 2

Comparisons of cardiorespiratory and muscular endurance parameters of boys with and without ID.

\begin{tabular}{lcc}
\hline Parameters & Boys with DI $(\mathrm{n}=40)$ & Boys without ID $(\mathrm{n}=30)$ \\
\hline Flexibility $(\mathrm{cm})$ & $9.67 \pm 3.25$ & $11.43 \pm 1.66$ \\
Endurance of muscular strength $(\mathrm{nbr} / 30 \mathrm{sec})$ & $8.23 \pm 4.56$ & $13.67 \pm 2.19^{*}$ \\
Explosive force (cm) & $151.6 \pm 18.3$ & $153.02 \pm 10.4$ \\
Isométric force (newton) & $24.41 \pm 5.85$ & $27.93 \pm 1.32^{*}$ \\
Distance traveled (m) & $181.79 \pm 8.59$ & $186.81 \pm 12.02^{*}$ \\
VO $2 \mathrm{max}(\mathrm{ml} / \mathrm{kg} / \mathrm{min})$ & $27.10 \pm 2.74$ & $34.91 \pm 2.51^{*}$ \\
\hline
\end{tabular}

${ }^{*} p<0.01$, ID: Intellectual disability 
Table 3

Comparison of fitness parameters of girls with and without.

\begin{tabular}{lcc}
\hline Parameters & Girls with ID $(\mathrm{n}=30)$ & Girls without ID $(\mathrm{n}=30)$ \\
\hline Souplesse $(\mathrm{cm})$ & $11.02 \pm 1.10$ & $12.35 \pm 2.9$ \\
Endurance of muscular stength (nbr/30sec) & $6.01 \pm 1.02$ & $10.71 \pm 5.18^{* * *}$ \\
Explosive force (cm) & $109.3 \pm 3.7$ & $112.4 \pm 11.3$ \\
Isométric force (newton) & $20.6 \pm 3.41$ & $25.9 \pm 1.16^{* *}$ \\
Distance traveled $(\mathrm{m})$ & $139.33 \pm 9.19$ & $144.02 \pm 13.8^{* *}$ \\
$\mathrm{VO}$ max $(\mathrm{ml} / \mathrm{kg} / \mathrm{min})$ & $26.5 \pm 1.63$ & $32.75 \pm 4.11^{*}$ \\
\hline${ }^{*} p<0.01$ & &
\end{tabular}

Table 3 shows that girls with intellectual disabilities have significantly lower muscular endurance, explosive strength, isometric strength and cardiorespiratory fitness compared to girls without intellectual disabilities.

\section{Discussion}

Physical fitness during childhood or adolescence is a predictor of good health in adulthood (Ortega et al., 2011). Cardiorespiratory endurance and muscle strength are among the components of physical fitness most often recommended to establish a prognosis for chronic disease risk (Bégarie et al., 2011). The objective of this study was to evaluate the physical condition of sedentary children and adolescents with intellectual disabilities, schooled in the city of Kinshasa province in comparison with children without ID. Our results generally show that sedentary children and adolescents with intellectual disabilities have a significantly lower physical condition compared to the control group. There are many studies on the fitness levels of children with DI. These studies showed that children with ID had lower fitness levels than children without ID (Un \& Erbahceci, 2001; Fernhall \& Pitetti, 2000; Pitetti et al., 2001; Hilgenkamp et al., 2012). These lower fitness levels would be associated with lower motivation and a lower level of AP in children with ID, but also induced by lack of sports practice since infancy. Fitness level is the ability to perform physical activity by bringing into play a full range of physiological and psychological resources. Fitness is considered an indicator of an individual's health (Skowronski et al., 2009). Insufficiently stimulated, the physical condition deteriorates. In this sense, WHO recommends physical activity of at least 30 min / day for adults or $60 \mathrm{~min}$ / day for children (World Health Organization, 2010). These recommendations do not exist for people with ID, but in terms of public health it is obvious that it is necessary to provide regular and sufficient physical activity to these people.

Pitetti \& Campbell (1991) compared the cardiorespiratory endurance of individuals with and without ID and found that children's cardiorespiratory endurance with DI was 20 to $43 \%$ less than that of the general population. In our study the low values of $\mathrm{VO}_{2}$ can be linked in particular by a lack of sports educators for children with special needs; a lack of sports facilities (club, gym ...); a lack of financial means and "sports culture" within families.

Flexibility is affected by physical inactivity. It also varies with gender, age, muscle and joint aging. Flexibility is a determining factor for the unrestricted realization of activities of daily living in the general population. Chaiwanichsiri et al. (2000) showed that the flexibility of children with DI was lower than that of the control population. These results were explained by the fact that 
subjects with ID have a delay in understanding and lead a more sedentary lifestyle than their peers.

Graham \& Reid (2000) reported trunk flexibility results in children with ID. These authors specify that the scores in their studies are lower than the minimum retained. In our study, there was no significant difference $(p>0.05)$ between the two groups on this flexibility test (Graham \& Reid, 2000). The reason could be related to the sedentary lifestyle of both groups.

The comparison between girls with no DI revealed that girls without ID had significantly greater muscular strength, isometric force, distance traveled and cardiorespiratory endurance than those with ID ( $p<0.001)$. This could be justified by the fact that girls are of course naturally weak and when the DI is added this worsens the situation further.

Activities of daily living require not only strength and cardiorespiratory endurance, but also power. Guidetti et al. (2010) found, using the long jump test, that children with inactive ID had significantly lower leg explosive power than children without ID. Mean jump length was $75.6 \pm$ $32.0 \mathrm{~cm}$ for children with IDD and $119.7 \pm 38.7 \mathrm{~cm}$ for children without ID. In our study, the explosive power of the legs was also evaluated. We did not observe any significant difference in the comparison between girls or boys. Although we did not find statistical differences, nevertheless girls and boys with DI had lower mean values than those without ID. These low motor abilities observed in children with ID may be related to their reduced ability to engage in sufficient physical activity in relation to their level of cognition. In fact, lack of motor stimulation in children probably leads to less muscle mass development in the lower limbs.

Muscular endurance is essential for the performance of daily life and leisure activities, as well as for the ability to work. Lower muscle endurance may limit the physical activity of people with ID. A positive correlation has been established between muscular endurance and industrial work performance (Horvat \& Franklin, 2001). Graham \& Reid (2000) measured muscle endurance using push-up and straightening tests and found that the average number of pumps and straightening performed on children with ID was $11.7 \pm 11.4$ and $10.6 \pm 7.6$. These results were lower than those of the reference population. In our study, endurance of the abdominal muscles was measured by the straightening test. The average number of recovery was significantly higher for the control group compared to the group of children with DI. The results of this study are therefore similar to those reported by Graham \& Reid (2000). This would be explained by the fact that children with ID have a low level of cognition which consequently influences their test results.

\section{Conclusion}

This study showed that children and adolescents with ID compared to their peers without ID have a low cardiorespiratory and muscular level. This physical condition is gender-specific, and is in favor of boys over girls. A physical activity program is needed to improve the physical condition of children and adolescents with ID to prevent the development of pathologies induced sedentary lifestyle.

\section{Acknowledgement}

We thank the authorities of Tuendeley Medical Institute and Bopikiliki Institute for accepting the realization of this study in their respective establishments and for children and adolescents with and without DI for their collaboration.

\section{Declaration of conflicts of interest}

The authors declare that they have no conflicts of interest in relation to this article. 


\section{References}

American College of Sports Medicine. Physical Fitness Assessment Manual. 4th ed., Baltimore, MD, USA: Lippincott Williams \& Wilkins, 2014.

Bégarie J, Maïano C, Ninot G. Concept de soi physique et adolescents présentant une déficience intellectuelle: effets de l'âge, du genre et de la catégorie de poids. Rev Canadienne de Psych, 2011; 56(3): 179-186.

Bricout VA, Pace M, Dumortier L, Baileuil F, FavreJuvin A, Guinot M. Reduced Cardiorespiratory Capacity in Children with Autism Spectrum Disorders. J Clin Med, 2018; 7: 361.

Chaiwanichsiri D, Sanguanrungsirikul S, Suwannakul W. Poor physical fitness of adolescents with mental retardation at Rajanakul School, Bangkok. J Med Ass Thailand, 2000; 83: 1387-1392.

Fernhall B, Pitetti KH. Leg strength related to endurance run performance in children and adolescents with mental retardation. Pediatr Exerc Sci, 2000; 12: 324323.

Gonzalez-Aguero A, Vicente-Rodriguez G, Moreno LA, Guerra-Balic M, Ara I, Casajus JA. Health-related physical fitness in children and adolescents with Down syndrome and response to training. Scand J Med Sci Sports, 2010; 23: 475-488.

Graham A, Reid G. Physical fitness of adults with an intellectual disability: A 13-year follow-up study. Res Quart Exerc and Sport, 2000; 71(5): 152-161.

Guidetti L, Franciosi E, Gallotta MC, Emerenziani GP, Baldari C. Could sports influence fitness and health of adults with mental retardation? Res Dev Dis, 2010; 31(10): 1070-1075.

Hilgenkamp Y, Bleyenheuft L, Warnery A, Desplan J. Alcoolo dépendants sevrés, effets d'un passage en moyen séjour sur l'état dépressif et l'estime de soi. Alcoologie et Addictologie, 2012; 25(4): 289-294.

Hinckson EA, Dickinson A, Water T, Sands M, Penman L. Physical activity, dietary habits and overall health in overweight and obese children and youth with intellectual disability or autism. Res Dev Dis, 2013; 34(4): 1170-1178.

Horvat M, Franklin C. The effects of the environment on physical activity patterns of children with mental retardation. Res Quart Exerc Sport, 2001; 72(8): 189195.

Huffman M, Barzilai N. Role of visceral adipose tissue in aging. Biochem Biophy Acta, 2009; 1790: 11171123.

Institut national de la statistique (ins), unicef, Enquête Nationale à indicateurs multiples sur la situation des enfants et des femmes, MICS, 2010.

Lin JD, Lin PY, Lin LP, Chang YY, Wu SR, Wu JL. Physical activity and its determinants among adolescents with intellectual disabilities. Res Dev Dis, 2010; 31: 263-269.

Lotan M, Isakov E, Kessel S, Merrick J. Physical fitness and functional ability of children with intellectual disability: effects of a short-term daily treadmill intervention. Sc W J, 2004; 7(4): 449-457.

Ninot G, Maïan C. Long-term effects of athletics meet on the perceived competence of individuals with intellectual disabilities. Res Dev Dis, 2008; 28(2): 176186.

Ortega FB, Artero EG, Ruiz JR, España-Romero V, Jiménez-Pavón D, Vicente-Rodriguez G, Moreno LA et al. Physical fitness levels among European adolescents: the HELENA study. Br J Sports Med, 2011; 45: 20-29.

Pace M, Bricout VA. Low heart rate response of children with autism spectrum disorders in comparison to controls during physical exercise. Physiol Behav, 2015; 141: 63-68.

Pitetti KH, Campbell KD. Mental retarded individualsA population at risk? Med Sci Sports Exerc, 1991; 23: 586-593.

Pitetti KH, Yarmer DA, Fernhall B. Cardiovascular fitness and body composition of youth with and without mental retardation. Adapt Phys Activ Quart, 2001; 18: 127-121.

Pitetti KH. A reliable isokinetic strength test for arm and leg musculature for mildly mentally retarded adults. Arch Phys Med and Rehab, 1990; 71: 669-672.

Politte L, Dougle J. Atypical antipsychotics in the treatment of children and adolescents with pervasive developmental disorders. Psycho Pharmacol, 2014; 231: 1023-1036.

Salaün L, Berthouze-Aranda S. Condition physique et niveau d'activité physique d'enfants présentant des 
troubles des fonctions cognitives. Sciences et Sports, 2011; 26: 212-215.

Secchi JD, García GC, España-Romero V, CastroPiñero J. Physical fitness and future cardiovascular risk in argentine children and adolescents: an introduction to the ALPHA test battery. Arch Argent Pediatr, 2014; 112: 132-140.

Sinivasan SM, Pescatello LS, Bhat AN. Current perspectives on physical activity and exercise. Recommendations for obesity and physical fitness in children and adolescents with autism spectrum disorders. Phys Ther, 2014; 22(2): 73-79.

Skowronski M, Horvat M, Nocera J, Roswal G, Scroce R. Eurofit special: European fitness battery score variation among individuals with intellectual disability. Adapt Phys Activ Quart, 2009; 126: 54-67.

Un N, Erbahceci F. The evaluation of reaction time on mentally retarded children. Pediatr Rehab, 2001; 4(8): 17-20.
Welk GJ, Meredith MD, Ihmels M, Seeger C. Distribution of health-related physical fitness in Texas youth: a demographic and geographic analysis. Res Q Exerc Sport, 2010; 81: 6-15.

World Health Organization. Global Recommendations on Physical Activity for Health: Geneva, Switzerland, 2010; pp. 1-58.

Owen N, Salmon J, Koohsari MJ, Turrell G, Giles-Corti B. Sedentary behaviour and health: mapping environmental and social contexts to underpin chronic disease prevention. Br J Sports Med, 2014; 48(3): 174-177.

World health Organization. Stratégie mondiale pour l'alimentation, l'exercice physique et la santé. Activité physique pour lesjeunes.2015.8-10-2015. http://www.who.int/dietphysicalactivity/factsheet_ young_people/fr/

World health Organization. 10 faits sur l'exercice physique. 2014. http://www.who.int/features/factfiles/ physical_activity/fr 